\title{
The social brain
}

\author{
Janna M. Glozman ${ }^{a}$, Pavel Krukow ${ }^{b}$ \\ ${ }^{a}$ Lomonosov Moscow State University, Moscow, Russia \\ ${ }^{b}$ Maria Curie-Sklodowska University in Lublin, Lublin, Poland
}

\begin{abstract}
This article considers different aspects of the new neuropsychological theory of the social brain and its relationship to Luria's and Vygotsky's understanding of a human as a social and biological unity. The main functions of social cognition are described. Five aspects of these functions and five groups of evidence are analyzed: the negative consequences of brain damage on social behavior and social cognition; the social features of early-childhood development; the double interaction between brain maturation and the formation of mental functions; the negative consequences of social neglect on brain development; and the social and cultural specificity of neuropsychological assessment methods. The proposed new understanding of the social brain is as the social and cultural regulator of brain functioning.
\end{abstract}

Keywords: neuropsychology, cultural-historical approach, brain functioning, social cognition

The term social brain was introduced into neuropsychology by Gazzaniga (1985) in his studies of emotional and social communication disturbances after righthemisphere damages.

Later this term was used to show how the human brain processes social information and regulates the mind as a whole (Brothers, 1990; Brüne, Ribbert, \& Schiefenhovel, 2003; Dunbar, Gamble, \& Gowlett, 2010; Insel \& Fernald, 2004).

Two theories are used to explain the organization of social cognition; the first is theory of mind (Weed, McGregor, Nielsen, Roepstorff, \& Frith, 2010). In this theory, social cognition is understood as a typical module, separated from any other processes, that operates with specific knowledge. People have a definite theory about inner, nonobservable mental states that generate observable behaviors. Theory of mind is closely related to, or even dependent on, communication

The research reported in this article was part of a scientific collaboration between the Psychology Department of Lomonosov Moscow State University and the Department of Clinical Psychology and Neuropsychology of Maria Curie-Sklodowska University in Lublin (Poland). 
and language. All acts of communication, such as using metaphors, humor, irony, and sarcastic phrases and having the conversational ability to make issues understandable to others, require constant awareness of the participants' states of mind (their knowledge, intentions, and beliefs). This theory also postulates that activating the theory of mind requires mobilization of some executive subsystems, such as cognitive plasticity, working memory, the inhibition of selected stimuli for the benefit of others, and the ability to use representations and metarepresentations (Aboulafia-Brakha, Christe, Martory, \& Annoni, 2011).

Disturbances of social cognition, an inability to understand the feelings of others, which is a manifestation of a lack of theory of mind, is one of the explanations for the behavioral disturbances in autism (Brownell, Griffin, Winner, Friedman, \& Happe, 2000; Nikolskaya et al., 2005). Neurovisualization techniques reveal in these patients an aborted development of the dendritic structure of the limbic system and an increase in the number of abnormal cells in the cerebellum (Joseph, 1999).

The second model for the organization of social cognition is simulation theory (Adolphs, Damasio, Tranel, Cooper, \& Damasio, 2000), which proposes that although mental states of others are not directly observable, it is possible to use our imagination and our mental states as a model for simulating the mental states of others. Simulation theory is connected to the discovery of "mirror neurons," which are localized in the premotor ventral cortex and partly in the parietal lobe (Rizzolatti, Fadiga, Gallese, \& Fogassi, 1996); mirror neurons are activated by the subject's own movement but also by observation of another person's movement. Mirror neurons are a kind of "translator" of observable behavior to inner, mental states.

Social cognition has the following main functions:

- integration of a complex situation into a meaningful whole, emotionally and socially

- evaluation of the situation on the basis of moral behavior

- self-regulation

The relationship between social cognition and social behavior is still largely unknown or is very complex and involved in connections with other regulatory processes. It is highly probable that there is no simple translation of social cognition into social behavior. But pathology in those two components leads to the interpersonal maladjustment of patients with brain injury.

Five aspects of the functioning of social cognition and five groups of evidence can be analyzed in studies of social cognition and the social brain:

1) the negative consequences of brain damage on social behavior and social cognition

2) the social features of early-childhood development

3) the double interaction between brain maturation and the formation of mental functions

4) the negative consequences of social neglect on brain development

5) the social and cultural specificity of neuropsychological assessment methods 


\section{Negative Consequences of Brain Damage on Social Behavior and Social Cognition}

Neuropsychological studies focusing on the location of brain structures whose failure specifically interferes with social functioning have emphasized the regulative role of the brain's frontal lobes and right hemisphere (Borod, Koff, \& Caron, 1983; Eslinger \& Geder, 2000; Herzyk, 2000; Lezak, 1986; Malloy, Bihrle, \& Duffy, 1993; Stuss \& Benson, 1984; Tompkins, 1997). The functions associated with the right hemisphere have even been described as a "buried treasure" (Perecman, 1983).

Suggested explanations for this role of the right hemisphere have referred to its functional specificity. Also, the right hemisphere has more associative areas than the left. This hemisphere is dominant for the perception of bodily images and for bodily sensations, which are the primary basis for generating affective experience. This claim was on the one hand extensively documented by Devinsky (2000); on the other hand, it points to the role of the so-called neurosomatic concepts, which emphasize the specific contribution of somatic, visceral processes in the brain's organization of cognition and affect. The best-known concept that belongs to the current neurosomatic trend is the somatic-marker hypothesis of Damasio (1999).

As O’Shanick and O'Shanick remark (1994), "personality change” resulting from brain damage and manifested mainly within interpersonal behaviors is considered by family and friends as the most serious problem of a patient with brain damage, even if the change occurs after 1, 5, or 15 years. Such a change also interferes with the efficiency of the neurorehabilitation of brain-damaged patients (Glass, Matchar, Belyea, \& Feussner, 1993; Lezak, 1986; Pãchalska, 2007).

A relatively new theoretical approach is neuropsychoanalysis-the study of the relationship between the structure and functions of the right hemisphere and social attachment —namely, coping with stress (Krukow, 2008; Schore, 1994).

To sum up the evidence for the negative consequences of brain damage on social behavior and social cognition one should mention:

- Disturbances in the expression of emotions and in the recognition of the mental state of others after right-hemisphere and frontal damage (the worst results for social behavior are seen in patients with frontal-lobe dysfunctions)

- Behavior disturbances (self-criticism, lack of accuracy in reactions to social stimuli) in the frontal syndrome (Luria, 1973)

- Affective disturbances in people with Parkinson's disease (Glozman, 2004)

- Disorders in the generation, recognition, and experience of fear and the expression of surprise in patients with bilateral amygdala damage (Ammerlaan, Hendriks, Colon, \& Kessels, 2008)

- Behavior and social-cognition disturbances after unilateral ischemic stroke in the area of the right middle cerebral artery (Krukow, 2013)

- Social consequences of ADHD (Glozman, 2012) 


\section{Social features of early-childhood development}

Investigations using functional neuroimaging have contributed a lot of information to the study of the neuronal organization of social cognition. Authors of neuroimaging studies emphasize the role of different frontal areas and of the superior temporal sulcus and temporo-parietal junction. The superior temporal sulcus is activated when a subject perceives biological motion. A newborn infant follows facelike stimuli and has no reactions to inanimate subjects (Goren, Sarty, \& Wu, 1975). The same neural structure is considered crucial to anthropomorphizing in adults, in which moving geometric shapes, active for about two minutes, are perceived by healthy people as animate beings that even have intentionality and personality . Studies show that the amygdala also plays an important role in anthropomorphizing (Heberlein \& Adolphs, 2004); the amygdala probably initiates the process of social cognition and is its most fundamental source (Grossman et al., 2000; Weed et al., 2010).

Despite the fact that the observed activation may be bilateral in nature, experiments have confirmed a right-hemisphere advantage for identifying biological motion (Saxe, 2006). This advantage may be due to special aspects of neuroanatomical and functional right-hemisphere development. According to Schore (1994) the right hemisphere develops in the first two years primarily as a result of child-mother attachment. This relationship is peculiarly stimulating, and within its framework various abilities of children are developed: in the beginning, perceiving and then distinguishing the mother from other people, especially her face and voice, and, later, recognizing her intentions and other forms of individual intellectual abilities. In this way, attachment is developmentally related to social cognition.

Very early a baby begins to differentiate human voices from other sounds. An interesting study done by Mampe, Friederici, Christophe, and Wermke (2009) showed that the first expressions of infants are socially influenced: newborns' cry melodies are shaped by their native language.

In addition, overloading the visual perception system by watching TV provokes the sensory deprivation of other systems of analysis-above all, motor functions and communication skills. Or a missed phase of crawling, sometimes induced by parents trying to prevent traumas or infections, provokes spatial disturbances (Glozman, 2012).

\section{Double interaction between brain maturation and the formation of mental functions}

Thus, we have the double interaction between brain maturation and the formation of mental functions: on the one hand, for the emergence of a function a certain degree of maturity of the nervous system is required; on the other hand, the selffunctioning of and the active, developing influence on a psychological function is conducive to the maturation of structural elements of the brain (Halperin, Zaporozhets, \& Karpova, 1978). "The effects of childhood environment, favorable or unfavorable, interact with all the processes of neurodevelopment (neurogenesis, migration, differentiation, arborization, synaptogenesis, synaptic sculpting and myelination" (Perry, 2002, p. 79). 
The expansion of the ratio of the neocortex to evolutionally older areas is most closely correlated with the size and complexity of the social group in which the human species evolved. In other words, the evolutionary development of the brain is the result of adaptation to social factors.

\section{Negative consequences of social neglect on brain development}

Therefore social neglect has very negative consequences on brain development, as was proved in comparative studies of the brains of 3-year-old normal and neglected children by Perry (2002). The size of the brain of a neglected child was significantly smaller than in normal children.

The author revealed also that the early removal of a child from a social situation unfavorable for development favors recovery .

\section{Social and cultural specificity of neuropsychological assessment methods}

It has been shown that well-educated but brain-impaired individuals show neuropsychological performance similar to that of non-brain-impaired but illiterate individuals (Puente, 2012).

Thus each neuropsychological test is culturally specific: in one culture it reveals a brain pathology; in another, a low level of education or a lack of skills. The same IQ score will qualify a subject as a genius compared with the middle level of his or her population and as mentally retarded in another culture. Spatial representations of a rural subject are different from those of an urban subject. There are also differences in the lateral organization of verbal functions (Ardila, 1995). Johnson (2006) described 62 culture-specific variables in psychometric tests administration and interpretation.

All norms for neuropsychological tests should be culture-specific to provide their validity. However, most test norms were received through assessment of white subjects from the middle class. The standard procedure of test administration does not provide its relevance to cultural standards. A test translated into another language needs a selection of new material corresponding to linguistic and cultural features.

The language of assessment is of paramount importance for bilingual subjects: often the results are worse if testing is not performed in the native (maternal) language. A comparative study of bilingual and monolingual children with the NEPSY battery revealed that bilingual children in various countries performed better on digital tests and in copying, while monolinguals predominated on verbal and visual attention tests (Garratt \& Kelly, 2008).

Cultural specificity is characteristic of both verbal and nonverbal tests. Visual images for naming as well as stories in pictures differ when using the same battery in different countries. The "broken window" story from the Luria battery is inappropriate for subjects who have never seen snow (David \& Glozman, 2010).

The procedure of assessment is also important. For instance, in a study by Serpell (1979) African and British children had to reproduce patterns with pen and paper as well as with wire. British children were better with pen and paper, while Africans had better results using wire. 
The time allowed for test completion, important for many psychometric tests, also depends on cultural traditions: the quick performance of mental tasks is common for American children from the first classes of school, while in the Russian school system more attention is paid in such activities to selectivity and stability, which interfere with speed. This difference explains why in a comparative assessment of two groups of students Americans did better than Russians in psychometric tests with limited time for completion (Agranovich, 2004).

Cross-cultural studies reveal that some neuropsychological tests are less influenced by cultural differences: for example, verbal-fluency tests, digit-span tests, memory tests, and the test of the "clock without hands" from the Luria battery (Agranovich, 2004).

Thus, the cultural specificity of neuropsychological assessment is both a social and an ethical problem. Cultural equality of tests is as important as their validity for assessment of brain functioning.

\section{Conclusion}

As far back as 1922 Luria proposed "a principle of real psychology": "to deal with the concrete personality, the living human being, as a biological, social and psychological unity" (1922/2003, p. 296). This principle can be considered a foundation of the cultural-historical approach in psychology, which was later developed by Luria together with Vygotsky (1930/1982), and it is, in particular, a foundation of cultural-historical neuropsychology, which studies the interactions of culture and brain functions. A definitive explanation of this approach was given in the last book by Luria; analyzing his own contributions to psychological science, he wrote, "We need to step outside the organism to discover the sources of specifically human forms of psychological activity" (1979, p. 43).

These ideas by Luria were developed in contemporary Western neuropsychology and neurosciences through the concept of the social brain. The social neuropsychological approach is essentially dominant in the newest Western neuroscientific literature. Nevertheless this concept was deeply influenced by narrow localization tendencies in Western neuropsychology, which looked predominantly for cerebral representations of different forms of social cognition and social behavior. Because of this search the participation of different cerebral structures in these processes was proved. Interaction between brain structures can take place at the level of neuroanatomical structures, functional systems, and neurochemical modulation.

The cultural-historical approach in neuropsychology signifies a change in the orientation of studies of the social brain from localization to problems in the social and cultural regulation of cerebral functions.

This is a potentially relevant perspective for further neuropsychological investigation: one should examine not only patients' cognitive and other regulatory processes but also their relationships with people with whom they interact at different levels of intimacy. This analysis should assess their behavior with a strong emphasis on ecological validity. Nowadays more and more rehabilitation programs use the holistic approach, often taking into account the interpersonal aspect (Jojek, 2008); interdisciplinary cooperation can develop programs combining cognitive therapy with a range of neuropsychoanalytic methods (Kaplan-Solms \& Solms, 2001). 
The correlation of cognition and social behavior assumes that patients who have difficulty in recognizing and understanding intentions and emotions are also judged as emotionally indifferent and as not exhibiting behaviors associated with emotional bonds. Patients who do not perceive the intentional behaviors of others are not able to respond in the manner expected.

To conclude, it is necessary to analyze the possibilities and limitations of the application of the social-brain concept and to answer some important questions:

- Does the assessment of social cognition bring new possibilities for clinical neuropsychological diagnosis?

(Most likely not: social cognition is connected to many structures)

- Are there possibilities for applying the results of social neuroscience in the rehabilitation of neurological and neuropsychiatric patients with disruptions of social behavior?

(Definitely yes)

- Are these results important for regulating a subject's health and quality of life?

(Definitely yes)

- Are they important for developmental neuropsychology?

(Definitely yes)

Thus, diagnosis and therapy should take into account patients' interpersonal relationships and, in particular, the ecological dimensions of neuropsychological assessment as a way to understand "the interdependence of the individual mind and the culture that enabled that mind to grow in a manner that recognizes and copes with the complexities of the world, physical and social alike" (Bruner, 2004, p. xii).

This understanding can permit us to answer the question: What can neuropsychology do for our culture, for social life?

\section{Acknowledgments}

This study was supported by Russian Humanitarian Science Foundation (RHSF) project \# 13-06-00570.

\section{References}

Aboulafia-Brakha, T., Christe, B., Martory, M.-D., \& Annoni, J.-M. (2011). Theory of mind tasks and executive functions: A systematic review of group studies in neurology. Journal of $\mathrm{Neu}$ ropsychology, 5, 39-55. doi: 10.1348/174866410X533660

Adolphs, R., Damasio, H., Tranel, D., Cooper, G., \& Damasio, A. R. (2000). A role for somatosensory cortices in the visual recognition of emotions as revealed by three-dimensional lesion mapping. Journal of Neuroscience, 20, 2683-2690.

Agranovich, A. (2004). Cross-cultural differences in neuropsychological performance: A comparison between Russian and American samples. In T. V. Akhutina, J. M. Glozman, L. I. Moskovich, \& D. Robbins (Eds.), A. R. Luria and contemporary psychology: Festschrift celebrating the centennial of the birth of Luria (pp. 181-188). New York: Nova Science. 
Ammerlaan, E., Hendriks, M., Colon, A., \& Kessels, P. (2008). Emotion perception and interpersonal behavior in epilepsy patients after unilateral amygdalohippocampectomy. Acta Neurobiologiae Experimentalis, 68, 214-218.

Ardila, A. (1995). Directions of research in cross-cultural neuropsychology. Journal of Clinical and Experimental Neuropsychology, 17, 143-150. doi: 10.1080/13803399508406589

Borod, J. C., Koff, E., \& Caron, H. S. (1983). Right hemisphere specialization for expression and appreciation of emotion: A focus on the face. In E. Perecman (Ed.), Cognitive processing in the right hemisphere (pp. 83-110). New York, London: Academic Press.

Brothers, L. (1990) The social brain: A project for integrating primate behavior and neurophysiology in a new domain. Concepts in Neuroscience, 1, 27-51.

Brownell, H. H., Griffin, R., Winner, E., Friedman, O., \& Happe, F. (2000). Cerebral lateralization and theory of mind. In S. Baron-Cohen, H. Tager-Flusberg, \& D. Cohen (Eds.), Understanding other minds: Perspectives from developmental cognitive neuroscience (2nd ed., pp. 306-333). Oxford: Oxford University Press.

Brüne, M., Ribbert, H., \& Schiefenhovel, W. (2003). Social brain: Evolution and pathology. New York: Wiley. doi: 10.1002/0470867221

Bruner, J. (2004). Preface. In T. V. Akhutina, J. M. Glozman, L. I. Moskovich, \& D. Robbins (Eds.), A. R. Luria and contemporary psychology: Festschrift celebrating the centennial of the birth of Luria. New York: Nova Science.

Damasio, A. (1999). Biãd kartezjusza. [Descartes's error]. Warsaw: Dom Wydawniczy Rebis.

David, J., \& Glozman, J. M. (2010). Rosiysko-Portugalskyy opyt neiropsikhologicheskogo obsledovania doshkolnikov [Converging impressions in neuropsychological assessment of preschoolers in Russia and Portugal]. Vestnik Moskovskogo Universiteta, Series 14: Psykhologia [Moscow University Psychology Bulletin], 1, 117-124.

Devinsky, O. (2000). Right cerebral hemisphere dominance for a sense of corporeal and emotional self. Epilepsy and Behavior, 1, 60-73. doi: 10.1006/ebeh.2000.0025

Dunbar, R., Gamble, C., \& Gowlett, J. (2010). Social brain, distributed mind. Oxford: Oxford University Press. doi: 10.5871/bacad/9780197264522.001.0001

Eslinger, P. J., \& Geder, L. (2000). Behavioral and emotional changes after focal frontal lobe damage. In J. Bogusslavsky \& J. L. Cummings (Eds.), Behavior and mood disorders in focal brain lesions (pp. 217-260). Cambridge: Cambridge University Press.

Garratt, L., \& Kelly, T. (2008). To what extent does bilingualism affect children's performance on the NEPSY? Child neuropsychology, 14(1), 71-81. doi: 10.1080/09297040701218405

Gazzaniga, M. (1985). The social brain: Discovering the networks of the mind. New York: Basic Books.

Glass, T. A., Matchar, D. B., Belyea, M., \& Feussner, J. R. (1993). Impact of social support on outcome in first stroke. Stroke, 24, 64-70. doi: 10.1161/01.STR.24.1.64

Glozman, J. M. (2004). Communication disorders and personality. New York: Kluwer, Plenum. doi: 10.1007/978-1-4419-9288-8

Glozman, J. M. (2012). Developmental neuropsychology. London, New York: Psychology Press, Taylor and Francis.

Goren, C. C., Sarty, M., \& Wu, P. Y. (1975). Visual following and pattern discrimination of facelike stimuli by newborn infants. Pediatrics, 56(4), 544-549.

Grossman, E., Donnelly, M., Price, R., Pickens, D., Morgan, V., \& Neighbor, G. (2000). Brain areas involved in perception of biological motion. Journal of Cognitive Neuroscience, 12(5), 711-720. doi: 10.1162/089892900562417

Halperin, P. Ya., Zaporozhets, A. V., \& Karpova, S. N. (1978). Aktualniye problemy detskoy psykhologii [Actual problems of developmental psychology]. Moscow: Moscow University Press. 
Heberlein, A. S., \& Adolphs, R. (2004). Impaired spontaneous anthropomorphizing despite intact perception and social knowledge. Proceedings of the National Academy of Sciences of the United States of America, 101(19), 7487-7491. doi: 10.1073/pnas.0308220101

Herzyk, A. (2000). Myzg - emocje - uczucia. Analiza neuropsychologiczna [Brain - emotions feelings. A neuropsychological analysis]. Lublin: Wydawnictwo UMCS.

Insel, T. R., \& Fernald, R. D. (2004). How the brain processes social information: Searching for the social brain. Annual Review of Neuroscience, 27(1), 697-722. doi: 10.1146/annurev. neuro.27.070203.144148

Johnson, T. (2006). Methods and frameworks for cross-cultural measurements. Medical Care, 44(11), suppl. 3, 17-20. doi: 10.1097/01.mlr.0000245424.16482.f1

Jojek, E. (2008). Rehabilitacja neuropsychologiczna osyb po uszkodzeniach prawej pyikuli myzgu [Neuropsychological rehabilitation of patients with right-hemisphere injury]. In E. Jojek \& A. Bolewska (Eds.), Wybrane zagadnienia rehabilitacji neuropsychologicznej [Selected problems of neuropsychological rehabilitation] (pp. 72-95). Warsaw: Wydawnictwo Naukowe Scholar.

Joseph, R. M. (1999). Neuropsychological frameworks for understanding autism. International Representation of Psychiatry, 11, 309-325. doi: 10.1080/09540269974195

Kaplan-Solms, K., \& Solms, M. (2001). Clinical studies in neuro-psychoanalysis: Introduction to a depth neuropsychology. London: Karnac Books.

Krukow, P. (2008). Kliniczne znaczenie aktualnych badac nad neuroetologiã i neuropsychologiã przywiãzania [Clinical significance of modern neuroethological and neuropsychological studies of social attachment]. Psychologia - Etologia - Genetyka [Psychology - Ethology Genetics], 17, 39-57.

Krukow, P. (2013). Neuropsychological determinants of social functioning in patients with right hemisphere ischemic damage - clinical applications. Polish Journal of Applied Psychology, 10(1), 21-47.

Lezak, M. D. (1986). Psychological implications of traumatic brain damage for the patient's family. Rehabilitation Psychology, 31, 241-250.

Luria, A. R. (1973). The working brain. An introduction to neuropsychology. London: Penguin Books.

Luria, A. R. (1979). The making of mind: A personal account of Soviet psychology. Cambridge, MA: Harvard University Press.

Luria, A. R. (1922/2003). Printsipy realnoy psykhologii [The principles of real psychology]. In J. M. Glozman, D. A. Leontiev, \& A. G. Radkobskaya (Eds.), A. R. Luria. Psychological tribute (pp. 295-384). Moscow: Smysl.

Malloy, P., Bihrle, A., \& Duffy, J. (1993). The orbitomedial frontal syndrome. Archives of Clinical Neuropsychology, 8, 185-201.

Mampe, B., Friederici, A. D., Christophe, A., \& Wermke K. (2009). Newborns' cry melody is shaped by their native language. Current Biology, 19, 1994-1997. doi: 10.1016/j. cub.2009.09.064

Nikolskaya, O. S., Baenskaya, E. P., Libling, M. M., Kostin, I. A., Vedenina, M. U., Arshatskii, A. V., \& Arshatskaya, O. S. (2005). Deti i podrostki sautismom. Psikhologicheskoye soprovojdeniye [Children and teenagers with autism. Psychological help]. Moscow: Terevinf.

O’Shanick, G. T., \& O'Shanick, A. M. (1994). Personality and intellectual changes. In J. M. Silver, S. C. Yudofsky, \& R. E. Hales (Eds.) Neuropsychiatry of traumatic brain injury (pp. 163-188). Washington, DC: American Psychiatric Press.

Pãchalska, M. (2007). Neuropsychologia kliniczna. Urazy myzgu, t. 2. Procesy komunikacyjne $i$ powryt do spoieczecstwa [Clinical neuropsychology. Traumatic brain injuries (Vol. 2). Communication processes and return to society]. Warsaw: Wydawnictwo Naukowe PWN. 
Perecman, E. (1983). Introduction: Discovering buried treasure-a look at the cognitive potential of the right hemisphere. In E. Perecman (Ed.) Cognitive processing in the right hemisphere (pp. 1-18). New York, London: Academic Press.

Perry, B. D. (2002). What childhood neglect tells us about nature and nurture. Brain and Mind, 3, 79-100. doi: 10.1023/A:1016557824657

Puente, A. (2012, November). The cultural in cross-cultural neuropsychology. Paper presented at the Moscow International Congress Devoted to the 110th Anniversary of Luria's Birth, Moscow.

Rizzolatti, G., Fadiga, L., Gallese, V., \& Fogassi, L. (1996). Premotor cortex and the recognition of motor actions. Cognitive Brain Research, 3, 131-141. doi: 10.1016/0926-6410(95)00038-0

Saxe, R. (2006). Uniquely human social cognition. Current Opinion in Neurobiology, 16(2), 235239. doi: 10.1016/j.conb.2006.03.001

Schore, A. N. (1994). Affect regulation and the origin of the self. The neurobiology of emotional development. Hillsdale, NJ: Erlbaum.

Serpell, R. (1979). How specific are perceptual skills? A cross-cultural study of pattern reproduction. British Journal of Psychology, 70, 365-380. doi: 10.1111/j.2044-8295.1979.tb01706.x

Stuss, D. T., \& Benson, D. F. (1984). Neuropsychological studies of the frontal lobes. Psychological Bulletin, 95, 3-28. doi: 10.1037/0033-2909.95.1.3

Tompkins, C. A. (1997). Right hemisphere communication disorders: Theory and management. San Diego, CA: Singular.

Vygotsky, L. S. (1930/1982). O psykhologicheskih systemakh [On psychological systems]. In L. S. Vygotsky, Collected papers (Vol. 1, pp. 109-132). Moscow: Pedagogika.

Weed, E., McGregor, W., Nielsen, J. F., Roepstorff, A., \& Frith, U. (2010). Theory of mind in adults with right hemisphere damage: What's the story? Brain \& Language, 113, 65-72. doi: 10.1016/j.bandl.2010.01.009 